\title{
Erratum to: Promoting Expressive Language in Young Children with or At-Risk for Autism Spectrum Disorder in a Preschool Classroom
}

\author{
Justin D. Lane ${ }^{1} \cdot$ Collin Shepley ${ }^{1} \cdot$ Rebecca Lieberman-Betz $^{2}$
}

Published online: 21 September 2016

(C) Springer Science+Business Media New York 2016

\section{Erratum to: J Autism Dev Disord \\ DOI 10.1007/s10803-016-2856-8}

In the Participants and Instructor section, under the subheading Greg the following statement was incorrectly described as "It should be noted that Greg previously participated in a research study in which language expansion was provided by the instructor (citation blinded for review)", instead of "It should be noted that Greg previously participated in a research study in which language expansion was provided by the instructor (Shepley et al. 2014)".

\section{Reference}

Shepley, C., Lane, J. D., \& Shepley, S. (2014). Teaching young children with social-communication delays to label actions using videos and language expansion models: A pilot study. Focus on Autism and Other Developmental Disabilities. doi:10.1177/1088357614552189.

The online version of the original article can be found under doi:10.1007/s10803-016-2856-8.

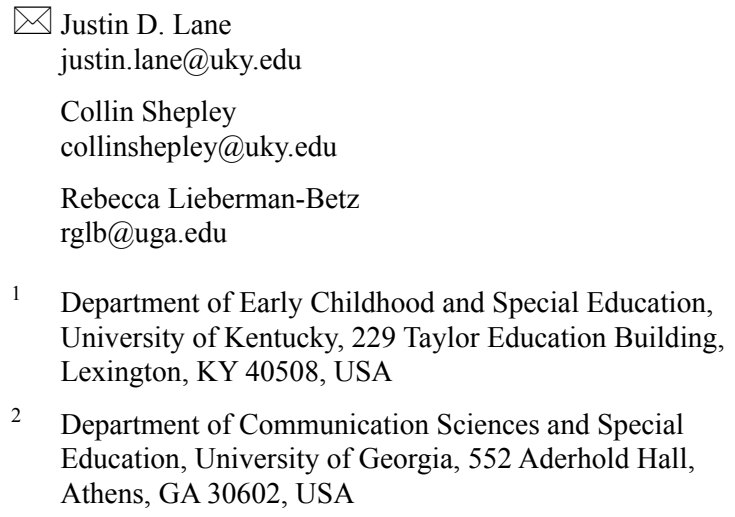

2 Department of Communication Sciences and Special Education, University of Georgia, 552 Aderhold Hall, Athens, GA 30602, USA 